\title{
ANALISIS CURAH HUJAN TERHADAP ZERO RUN OFF DENGAN MENGGUNAKAN METODE FUZZY PADA APLIKASI MATLAB
}

\author{
Tohazen $^{1}$, Teni Tresnawati ${ }^{2}$, dan Ahmad Tosin Alamsyah ${ }^{3}$ \\ 1,2,3 Polteknik Negeri Jakarta, Jurusan Teknik Elektro, Prodi Teknik Listrik, \\ Jl prof.Dr.GA Siwabessy, Kampus Baru UI Depok 16425 \\ e-mail: ${ }^{1}$ tohazen@gmail.com, ${ }^{3)}$ alamsyah.pnj@gmail.com
}

\begin{abstract}
Disaster has been a part of our life. It comes unexpectedly, whenever and wherever that is. Because of the uncertainty, we have to care and Parepare ourselves to face it. Indonesia as an archipelago has a high risk of disaster, especially flood, particularly in Jakarta. It happened regularly every year. It also happens in other cities in Indonesia.

Water scarcity in dry season and flood in rainy season become center of attention and influence us in many aspects of life. This study focus on on Prevention and Earl warning system. Online realtime information system is developer to get the data to be analized. The method is to capture the amount of rainwater volume in a watershed (Watershed), to calculate the amount of water as a contributor to flood / overflow of river water.

The solution is to use the absorption well as one of the ways to prevent flood disaster, to get the optimal value as a flooding solution, the formula of hydrological formula and rainfall analysis data have been captured by realtime and online-based monitoring tools.In order to get accurat result, fuzzy method is used on matlabstools.
\end{abstract}

Key words: floods, weather station ,zero run off, DAS

\begin{abstract}
ABSTRAK
Bencana sudah menjadi bagian dari kehidupan manusia yang datang tanpa diduga, dimana dan kapan saja terjadinya. Karena ketidak pastian tersebut, kita harus peduli dan menyiapkan diri untuk menghadapi bencana. Indonesia sebagai negara kepulauan yang rawan bencana terutama bencana banjir, dan ini menjadi seperti rutinitas setiap tahun terjadinya musibah banjir. Selain di Jakarta di daerah lain Indonesiapun terjadi bencana seperti ini bahkan seluruh dunia mengalami masalah bencana banjir ini, bahkan sampai memakan korban.

Kelangkaan air pada musim kemarau dan Banjir pada musim Hujan menjadi fokus perhatian dari sebagian masyarakat dan tanpa terasa berimbas pada hampir seluruh lapisan masyarakat. Sehingga peneliti juga sangat menekankan pada kedua bencana ini, dimana pada umumnya semua pihak berfokus pada peringatan dini bencana; terutama berfokus pada penanganan bencana banjir. Pada tulisan ini peneliti melakukan sesuatu hal yang berbeda dimana konsepnya adalah pencegahan agar bencana banjir berkurang atau seperti kondisi bumi sebelumnya dimana pada wilayah tersebut tidak terjadi bencana banjir.

Metode yang dilakukan adalah dengan menangkap jumlah volume air hujan pada suatu DAS (Daerah Aliran Sungai), untuk dihitung berapa jumlah air sebagai penyumbang banjir/meluapnya air sungai. Untuk itu dibutuhkan suatu sistem informasi berbasis realtime dan online agar mendapatkan data untuk dianalisa sebanyak mungkin.

Solusi yang dilakukan adalah menggunakan sumur resapan sebagai salah satu cara pencegahan bencana banjir, untuk mendapatkan nilai yang optimal sebagai solusi banjir maka dilakukan rumus rumus hidrologi serta data-data analisa curah hujan yang sudah ditangkap oleh perangkat monitoring realtime dan berbasis online, agar hasil perhitungan menjadi cukup akurat digunakan metode fuzzy pada tools matlabs.
\end{abstract}

Kata Kunci : Banjir, Bencana Banjir,weather station,zero run off,DAS

\section{PENDAHULUAN}

Bencana banjir telah menjadi persoalan tiada akhir bagi manusia di seluruh dunia dari dulu, sekarang dan yang akan datang. Di Indonesia, walaupun waktu terjadinya banjir dan besarannya bervariasi hampir semua daerah menghadapi bahaya banjir yang signifikan. Beberapa kejadian banjir 
besar seperti di Thailand, Cina dan beberapa kota besar di Indonesia menunjukkan bukti peningkatan tersebut (Robert J. Kodoatie, 2012 :1)

Ruang terbuka hijau merupakan wadah air yang sangat efektif. Dalam kawasan ini air hujan yang menjadi air premukaan akan tertahan karena lebatnya tanaman sehingga terjadi penurunan kecepatan runoff (aliran permukaan ) yang signifikan. Air permukaan yang tertahan akan berinfiltrasi ke dalam tanah mengisi wadah air dalam tanah yang berupa : soilzone dan groundwaterzone. Aliran soilwater bila sampai ke sungai disebut interflow (aliran antara) dan aliran groundwater bila sampai ke sungai disebut base flow (aliran dasar) (Kodoatie, 2012; Kodoatie dan Sjarief, 2010).

Pada penelitian yang lain kebanyakan mengupas tentang peringatan bencana banjir /early warning system, bedanya dengan penelitian ini adalah mendapatkan suatu nilai permasalahan banjir dan solusinya, sehingga kedepannya masalah banjir dapat tertangani.

Penelitian ini diharapkan dapat mengolah data dari sistem alat yang mampu mendeteksi kondisi curah hujan lebat tidaknya yang menyebabkan banjir , sehingga dapat diketahui pada suatu wilayah tersebut mulai banjir di titik curah hujan berapa ketinggian nya/jam. Logika fuzzy mudah dimengerti menurut Sri Kusuma Dewi (2010, p2). Karena logika fuzzy menggunakan dasar teori himpunan, maka konsep matematis yang mendasari penalaran fuzzy tersebut cukup mudah untuk dimengerti. Logika fuzzy mampu beradaptasi dengan perubahan-perubahan dan ketidakpastian yang menyertai permasalahan.
Peneliti lebih menekankan kepada berapa besar jumlah volume curah hujan ketika hujan terjadi pada suatu DAS (Daerah Aliran Sungai). Oleh karena itu peneliti membuat sendiri alat untuk memantau curah hujan dan tinggi air sungai pada suatu wilayah sehingga dapat di lihat apakah hujan saat ini membuat sungai meluap atau tidak.

Peneliti akan menggunakan metode fuzzy untuk mendapatkan curah hujan pada titik berapa yang menyebabkan banjir, dimana data curah hujannya secara realtime dikirim oleh alat ke web setiap 10 menit dan dipantau secara manual pada titik berapa mulai terjadinya banjir.

\section{METODE PENELITIAN}

Metode penelitian yang dilakukan terdiri dari tiga tahap, yaitu tahap pemasangan alat didaerah rawan banjir, pembuatan web monitoring dan terakhir analisa data curah hujan selama 6bulan. Pelaksanaan penelitian ini dilakukan di daerah Jakarta Selatan, 5 meter dari suangi DAS Mampang. Bagan umum penelitian ini dapat dilihat pada Gambar 1.

Dari Gambar 1 terlihat bahwa mikrokontroller membaca data curah hujan serta ketinggian air sungai, setelah itu datanya dikirim ke internet melalui gprs modem.

Gambar 2 menjelaskan bagaiamana kerangka dari metode fuzzy yang digunakan, yang terdiri dari factor, proposed methode, objective dan measurement 


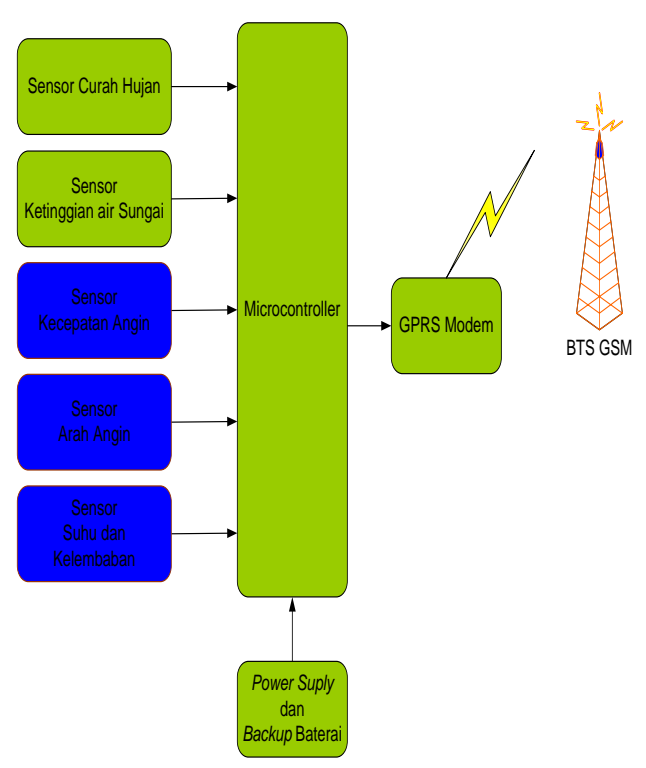

Gambar 1 Blok Diagram Sistem

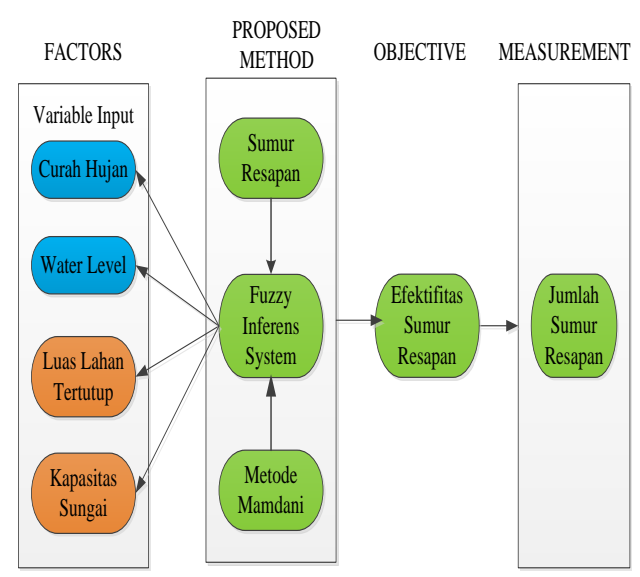

Gambar 2. Kerangka Pemikiran

\section{HASIL DAN PEMBAHASAN}

Sumur resapan adalah salah satu teknik yang paling efektif untuk menanggulangi banjir, karena berfungsi sebagai tabungan air hujan agar tidak mengalir ke sungai. Bila setiap bangunan yang tidak meresap, aliran air hujannya di masukan ke sumur resapan maka secara otomatis sungai tidak terlalu berat mendapatkan kiriman air hujan (runoff).

Untuk dapat menghitung sumur resapan yang menghasilkan nilai efektif maka diperlukan metode logika fuzzy untuk menghitungnya, dimana parameternya adalah luas wilayah DAS (Daerah aliran Sungai) / Catchment Area, data curah hujan, luas lahan tertutup pada DAS tersebut.

DAS Mampang memiliki data-data sebagai berikut: Luas Wilayah DAS 31,6 $\mathrm{Km}^{2}$, lebar sungai di jalan Kemang Timur adalah $7 \mathrm{~m}$, Kecepatan laju 1 $\mathrm{m}^{3} /$ detik, terdapat 6 titik banjir tahunan, salah satunya kemang timur lokasi penelitian, DAS Mampang mulai banjir dengan curah hujan diatas $\frac{40 \mathrm{~mm}}{\mathrm{Jam}}$ (Mei-Maret-2014) hingga 2018.

\section{1) Hardware}

Pengujian perangkat dibutuhkan untuk mendapatkan nilai curah hujan yang akurat, dengan menggerakkan tipping bucket dimana sudah terkalibrasi dengan pabrik, 0,2mm per satu ketukan.

Tabel 1. Kecepatan putar motor yang digunakan pada miniatur crane

\begin{tabular}{|l|l|l|}
\hline $\mathrm{N}$ & $\begin{array}{r}\text { Tippping } \\
\text { Bucke } \\
\mathrm{t}\end{array}$ & $\begin{array}{l}\text { Tampila } \\
\text { mikrokontrolle } \\
\mathrm{r}\end{array}$ \\
\hline 1 & 1 & $0.2 \mathrm{~mm}$ \\
\hline 2 & 2 & 0,4 \\
\hline 3 & 10 & 2 \\
\hline 4 & 200 & 40 \\
\hline
\end{tabular}

Pengukuran data diatas menandakan ketepatan sensor curah hujan/tipping bucket dengan data yang ada pada program mikrokontroller, terbukti bahwa sensor mempunyai kinerja yang akurat sesuai spesifikasi produk.

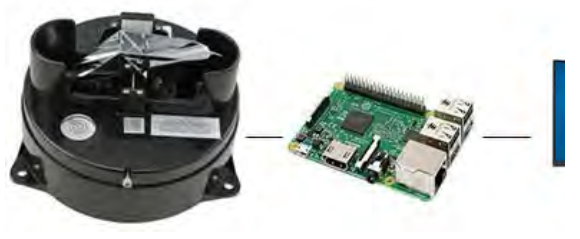

\section{Gambar 3. Pengujian Sensor Curah Hujan/ Tipping Bucket}




\section{2) Pengumpulan Data}

Sensor curah hujan dipilih karena data ini sangat penting untuk menentukan volume air yang turun ke suatu wilayah DAS, Water level diperlukan untuk memberikan informasi bahwa jalan sudah tergenang air.

Dari semesta pembicaraan tersebut diambil dengan asumsi Jumlah Sumur Resapan yang diteliti sebesar 100\% dengan nilai tertentu. Variable Curah Hujan dengan semesta pembicaraan mulai dari $0-100 \mathrm{~mm}$, variable luas lahan tertutup 1000m2 (bangunan gedung / rumah) dan variable output sumur resapan berupa nilai/ value.

\section{a) Pengolahan Data Awal}

Pada pengolahan data, data yang sudah dikumpulkan kemudian diolah dengan cara dilakukan seleksi atribut, yaitu menghapus data yang tidak diperlukan (tidak ada hujan) dan data yang redundant agar mengurangi data yang tidak relevan. Data disimpan dalam perangkat lunak microsoft office excel . Data yang tersimpan dalam excel terdiri dari variabel timestamp ,Curah Hujan , dan Water Level. Sampel data dipilah menjadi beberapa tabel data berdasarkan spesifikasi hujan ringan, sedang dan lebat :

a. Variable Curah Hujan terbagi dalam tiga himpunan, yaitu :

$\begin{array}{ll}\text { Ringan } & =[0-20] \\ \text { Sedang } & =[10-40] \\ \text { Lebat } & =[30-150]\end{array}$
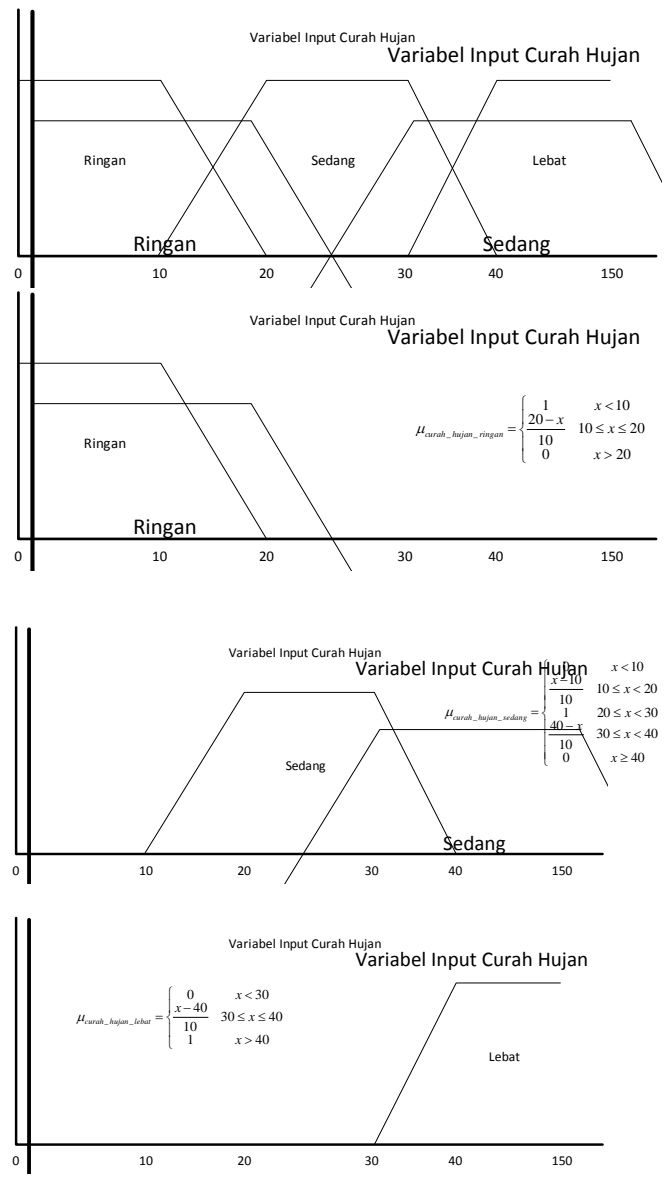

b. Variable Luas Lahan tertutup

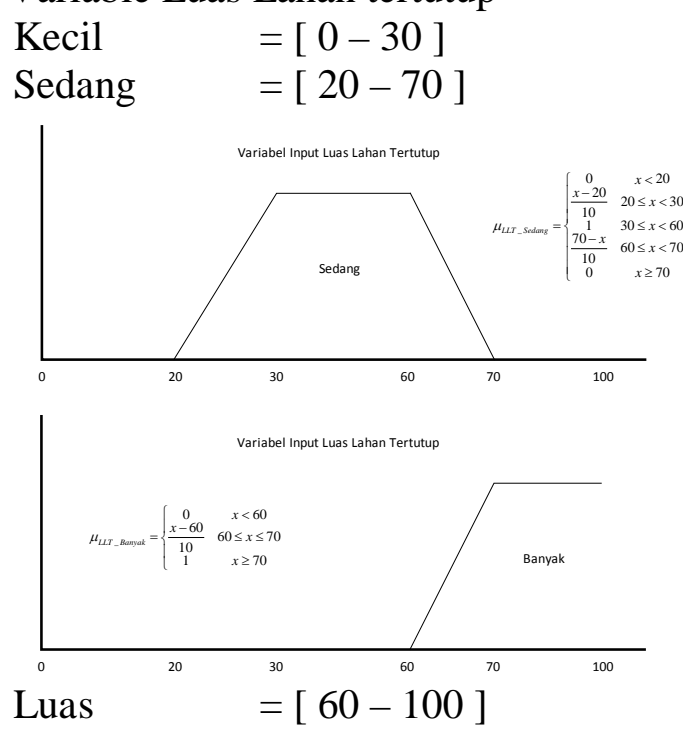




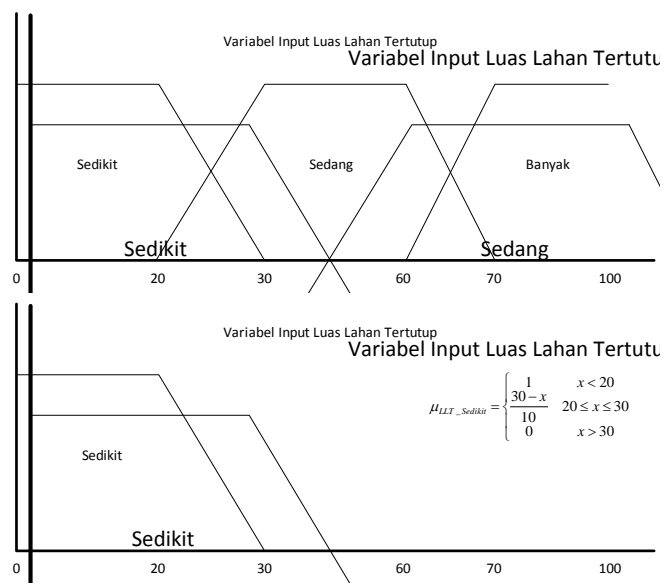

model Logika fuzzy.Alur kerjanya sebagai flowchart berikut:

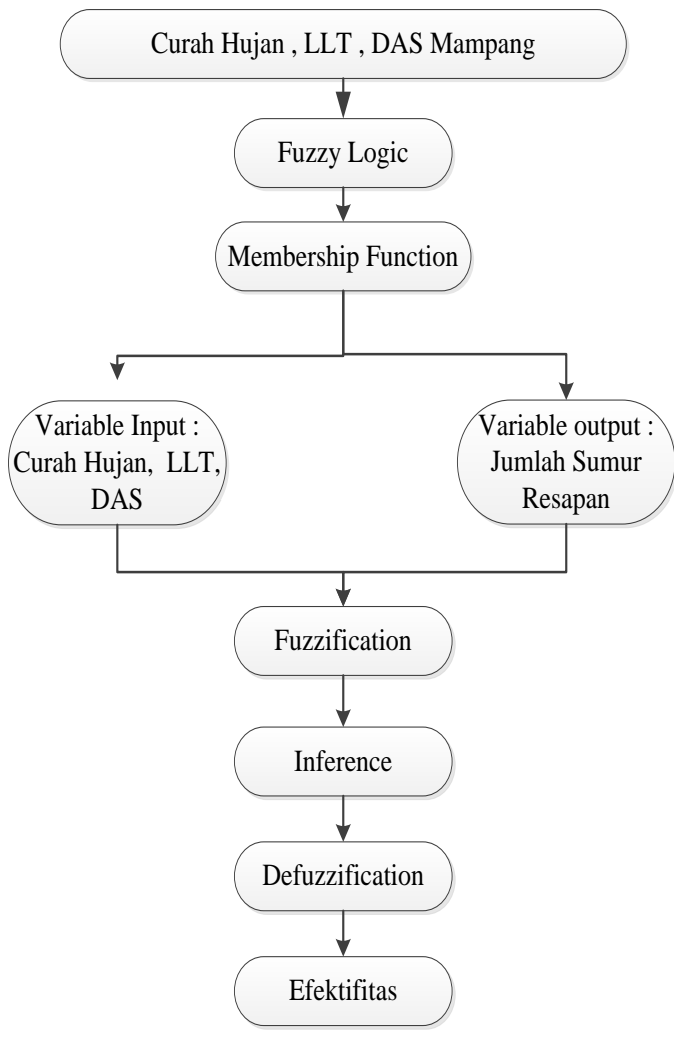

Gambar 4. Tatalaksana Sistem Fuzzy

\section{KESIMPULAN}

Data Sensor curah hujan dan sensor ketinggian air merupakan data yang sangat penting untuk menganalisa bagaiamana banjir itu terjadi serta bagaimana cara menanggulanginya, dimana selama ini data tersebut terpisah. Oleh karena itu, sistem ini menjadi lebih akurat ditambah lagi dengan data daya serap air suatu wilayah.

Dengan ditambahkannya sensor monitoring curah hujan ini akan menambah ke akuratan dalam hal menangani banjir, semakin banyak sensornya semakin bagus data yang akan diolah untuk menangulangi banjir.

Menggambarkan alur metode yang diusulkan dalam penelitian ini dengan menjelaskan cara kerja model yang diusulkan dan menggambarkannya dalam bentuk skema. Metode yang digunakan dalam penelitian ini adalah

Metode fuzzy ini menjadi suatu solusi yang cepat dan efesien untuk menangani data curah hujan yang besar / banyak. 
DAFTAR PUSTAKA

[1] Christian

Dawson,2009,"Project

W.

computing and information system",Second Edition. Addison Wesley

[2] Dr. Eng.Agus Naba. 2010. Belajar Cepat Fuzzy Logic Menggunakan Matlab. Andi Publisher

[3] Pemanfaatan Logika Fuzzy Untuk Sistem Prediksi Banjir. [01 Agustus 2016]

[4] Analisis Karakteristik Curah Hujan di Wilayah Kabupaten Garut Selatan [ 2014]

[5] Implementasi Logika Fuzzy Mamdani untuk mendeteksi Kerentanan Daerah Banjir di Semarang Utara [ November 2015]

[6] Penentuan Kerentanan Potensi Banjir dengan Logika Fuzzy Tsukamoto [2013 - 2014]

[7] Visualisasi Informasi Wilayah Resiko Banjir Berdasarkan Data Iklim Dengan Metode Fuzzy [ Juli 2016]

[8] Rokach, L.,2010,. Using Fuzzy Logic in Data Mining. In : Maimon, O.,Rokach, L., editors. Data Mining and Knowledge Discovery Handbook.Second Edition. London : Springer.

[9] M. Karamouz , A. Ahmadi . M.Akhbari 2011 , Gound Water Hydrology . Engineering, Planning and Management

[10] David K. Todd 1959 , Ground Water Hydrology

[11] Robert J.Kodoatie Dr Ir M Eng \& M Basoeki Dr Ir ,2005, Kajian Undang-Undang Sumber Daya Air

[12] Robert J.Kodoatie ,2013 , Rekayasa dan manajemen BANJIR KOTA

[13] Rohani Budi Prihatin, 2013, BANJIR JAKARTA Warisan Alam dan Upaya Pengendalian.
[14] Zaenuddin HM, 2013, BANJIR JAKARTA dari zaman Jendral JP Coen ( 1621) sampai Gubernur Jokowi ( 2013 ).

[15] Fathi M, Kianfar Kamran, et al , 2009, "Customers Fuzzy Clustering and Catalog SegmentationIn Customer Relationship Management”, Proceedings of the IEEE IEEM, p: $1234-1238$

[16] Aplikasi GIS Klasifikasi Tingkat Kerawanan Banjir Wilayah Kabupaten Bandung Menggunakan Metode Weighted Produc [ Indonesian Journal on Computing (Indo-JC) , 2017 ] 